the need for transplantable organs. Some estimates cited in this collection of essays suggest that the use of braininjured, but not brain dead, patients would increase the US donor pool by 20 per cent to 25 per cent, whilst in the Netherlands it is said that NHBCDs have raised the procurement of kidneys from 32 to 41 kidneys per million of the population each year. There are eleven active NHBCD programmes in Europe. In the UK NHBCDs are known as 'asystolic donors'. According to two American contributors an NHBCD programme operates in Leicester, England, with the approval of 'the local District Attorney'!

The book is evenly divided between supporters and critics of NHBCD protocols and the latter focus on the 'dead donor rule' or separation principle of transplant ethics, according to which vital organs must only be taken from dead patients; patients must not be killed by the removal of vital organs, and care for living patients should not be compromised by the needs of organ recipients. According to the Pittsburgh Protocol, criteria for death are met by evidence of absence of pulse pressure and two minutes of ventricular fibrillation, asystole, or electromagnetic disassociation. Critics insist that two minutes of pulselessness is an inadequate guarantee that auto-resuscitation will not occur and express reservations concerning the initiation of procedures to excise organs from patients with continuing brain function.

Opponents of brain death have asked whether the donors are really dead when evidence of irreversible loss of brain function has been demonstrated despite residual heart function. Now opponents of cardiocentric definitions of death may ask similar questions concerning donors with warm bodies and possibly healthy brains. One thing is certain: two minutes of pulseless apnoea in the operating theatre would not fulfil criteria for brainstem death. The Pittsburgh Protocol thus initiates a radical choice between two very distinct concepts of death.

As yet there has been little or no public discussion of NHBCDs and no media events comparable to the notorious BBC Panorama programme on brain death in 1983. But there is an urgent need for a full debate about organ removal after elective withdrawal of therapy and a firm commitment that guidelines which protect the dying are not discarded in favour of policies to increase the donor pool. This volume makes an excellent contribution to that debate.

DAVID LAMB

Reader in Philosophy,

Department of Biomedical Science and Biomedical Ethics,

University of Birmingham

\section{Bioethics for the people by the people}

Darryl R J Macer, Christchurch, New Zealand and Tsukuba, Japan, Eubios Ethics Institute, Japan, 1994, 452

pages, $£ 15.00$ sc.

This book consists in part of a survey of attitudes amongst a wider public than health care professionals and specialist bioethicists. It was conducted to discover what 'ordinary' people think bioethics is about, and what they regard the central issues as being. More than 6,000 questionnaires were returned from ten countries in 1993, and the book, to some extent, summarises the findings. It stems from a firm belief held by Darryl Macer that bioethics should not be the treasured possession of the professionals, nor of the Western world. Hence he adds to his own name on the cover, and through the book: 'with contributions from some friends, and from the people'.

It makes fascinating reading insofar as the material makes sense, but some of the time one suspects that the meaning of words is taken so differently between certain different cultures that some of the answers may not be comparable. That aside, this is an important attempt to give a picture of different attitudes. But an attempt is all it is. What one misses is true analysis. We get some moderately undigested data, and lots of diagrams to show variation. We also get a series of drawings produced by different country groups, and a series of answers to the questions simply reproduced. Though I am sure it is interesting to see how Macer and his colleagues conducted their survey, in fact it would be more useful to have less raw data, and more real analysis.

But that analysis is very difficult to do. Nevertheless, Macer demonstrates a general reluctance in all societies surveyed to allow the patenting of life, particularly of human genes, as well as high approval for gene therapy. There was also a split - usually within country groups - on eugenics, and a demonstrable general attitude of more shame and blame for the birth of a handicapped child in Asia than in Western societies.

Most of this is not news. Though it is important to understand what the main issues are which make people concerned in the bioethical field, one can often acquire that knowledge, at least in general, from reading the press of the country concerned. In Britain, for instance, there is concern about some of the more unusual aspects of IVF, but general admiration for the fact that we license and control centres performing such techniques. In fact, we know that from the media and from Parliament, though neither may be wholly representative of the people.

That element of consideration of the issues, by viewing the press and the political process, is sadly missing from Macer's book, as are other aspects of analysis, and true comparison between cultures. So, although this is a brave attempt, the work itself is not constructed to be readable, approachable, or even very useful in more than general terms for finding out what views, and deeply held cultural attitudes, exist in countries other than one's own. We need another volume, of analysis and comment, before we get a true picture.

JULIA NEUBERGER Chair, Camden and Islington Community Health Services NHS Trust

Moral matters: ethical issues in medicine and the life sciences

Arthur Caplan, New York, John

Wiley and Sons, 1995, 198 pages, $£ 12.50 \mathrm{sc}, \$ 19.95$.

The ninety-four essays included in this volume began their lives as newspaper articles. Nearly all of them first appeared, in the past few years, in the St Paul Pioneer Press, a newspaper based in St Paul, Minnesota. They were written by Arthur Caplan, Director of the Center for Bioethics, and Trustee Professor of Bioethics at the University of Pennsylvania. In his foreword, George D Lundberg, editor of The fournal of the American Medical Association rates Caplan 'in everyone's top five list of gurus in the American ethics mafia'. In Lundberg's estimation, 'Art Caplan is the ideal person to 
write such a comprehensive collection of essays as one finds in this book'.

Ninety-four essays covering ninetyfour topics is a lot of topics, even for a book on ethical issues in medicine and the life sciences. But the essays are extremely short, they are written in a direct, non-technical prose, and the range of topics ensures that the reader will never experience boredom. There are essays on topics as varied as 'Don't let State get a foothold in reproduction', 'Doctor stayed involved in life, not suicide', 'To be safe, screen risks, not workers', and 'Health-free motorcycle riding: a freedom too costly to society'.

Caplan's approach is to take a newspaper report, or a finding in a medical journal, and discuss its ethical implications. He believes that ethical conclusions are not a mere matter of opinion, but that they need to be argued for.

Caplan argues very convincingly for his own ethical positions. On abortion, for example, he holds that 'Assuring women the right to abortion acknowledges a right to make a choice fraught with uncertainty, doubt and moral ambiguity. It is a right that women must have but one they should not have to invoke' (page 12). On the issue of parenting and the use of donor sperm, he holds that it would not 'be wise to make rules about who can be a parent. This is a matter for public debate and, ultimately, legislation. A court is a lousy place to decide who can be a mom or dad' (page 16). Writing about the new reproductive technologies, Caplan offers the opinion that 'The central moral question of the 21 st century will be the degree to which genetic risk should influence decisions about bringing embryos to term' (page 37).

The essays on day-to-day medical care are, to say the least, eye-opening. Writing about the language of doctors and nurses, for example, Caplan advises that 'The most revealing language can be found in an intensive care unit. An elderly patient who is admitted with 'chartomegaly', a large stack of thick medical records from previous hospitalizations, has a very poor chance of surviving a stay in intensive care' (page 40). He also offers the following sobering advice about going into hospital: 'A good rule to follow about hospitals is never, ever go alone. If you are very ill, someone needs to be present to act as your advocate, gofer, and confidant. A good corollary to follow is don't go on a weekend. Staffing drops to a minimum and students are in charge' (page 42).

Caplan makes a particularly strong contribution to the debate on euthanasia. He draws attention to the fact that living wills have been found to have no influence on medical practice: 'One major reason was that few patients, even those who were clearly dying, actually lost the ability to make their wishes known' (page 70). He refers to a study done at the University of Washington at Seattle which found that 96 per cent of patients with terminal or life-threatening illnesses 'felt it would be worse to be kept alive under hopeless circumstances ... than it would be to actually die' (page 77). Caplan concludes that 'For many of us, there are things in life that are worse than death' (page 78). This is, perhaps, premature, because the study in question deals far more with dying than with death. If death is, in the words of Simone de Beauvoir, an eternity of nothingness, then it is very different from such dying experiences as 'the total loss of independence' and 'dying in a strange place' (page 77). The point is: death is not an unwanted experience but the complete absence of experience; in Larkin's words, the anaesthetic from which none come round.

The longest essay in the book deals with the question of whether personal responsibility should be taken into consideration in allocating scarce and expensive resources. Should alcoholics receive liver transplants? Caplan argues that they should, partly because 'Short-term survival rates for ... those with alcoholic hepatitis plus cirrhosis are not greatly different from those with only chronic cirrhosis' (page 151), and partly because so many illnesses are lifestyle illnesses that, if adopted, the principle of personal responsibility would license refusal of medical treatment to just about any citizen.

While Caplan sometimes errs on the side of caution (for example on biological wastes), I agree with just about all the particular ethical judgments he makes. However, I disagree with him on some more abstract philosophical and ideological matters. Caplan distinguishes between morality and ethics, but is reluctant to draw a distinction between personal and social ethics. 'Is it permissible for me to enter into a surrogacy agreement?' is a question in personal ethics; 'Should surrogacy be legalised?', on the other hand, is a question in social ethics. Caplan, I get the impression, would like to collapse these two categories into one, to make all ethical questions personal ones.

Caplan's predilection for doing so is probably not unrelated to his neoconservative position that the State should back-off from moral issues. $\mathrm{He}$ holds that citizens and legislators should be the final arbiters here, and that ethical issues must not be allowed to end up in the courts. But people go to court because they have grievances that otherwise cannot be settled, because legislation lacks clarity, or because political leaders lack moral courage. In general, social existence in the late 20 th century is so complex that the case for a minimal State cannot reasonably be sustained. That Caplan doesn't think this way may have something to do with the American-European divide: between a view of the State as the oppressor of self-directing individuals, and the्c concept of the State as a benign constitutional instrument. It would be regrettable if Caplan's frontier politics made European readers resistant to his ethical arguments, which are a model of sanity.

\section{JOSEPH MAHON Department of Philosophy, University College, Galway}

\section{Books: information and orders}

If you wish to order or require further information regarding the titles reviewed here, please write to or telephone the BMJ Bookshop, PO Box 295, London WC1H 9JR. Tel: 0171383 6244. Fax: 01713836662. Books are supplied post free in the UK and for BFPO addresses. Overseas customers should add 15 per cent for postage and packing. Payment can be made by cheque in sterling drawn on a UK bank or by credit card (Mastercard, Visa, or American Express, stating card number, expiry date, and full name (The price and availability are occasionally subject to revision by the publishers). 